\title{
ASSESSING THE ACCURACY OF SRTM DEM AND ASTER GDEM DATASETS FOR THE COASTAL ZONE OF SHANDONG PROVINCE, EASTERN CHINA
}

\author{
Shaopeng Luana ${ }^{c, d}$ \\ Xiyong $\mathrm{Hou}^{\mathrm{a}}$ \\ Yetang Wang ${ }^{\mathrm{b}}$ \\ a) Yantai Institute of Coastal Zone Research, Chinese Academy of Sciences, \\ Yantai, China \\ b) College of Population, Resources and Environment, Shandong Normal \\ University, Jinan, China \\ c) University of Chinese Academy of Sciences, Beijing, China \\ d) Geomatics Center of Yantai City
}

\begin{abstract}
This study assessed the performance of recently released 3 arc second SRTM DEM version 4.1 by CSI-CGIAR and 1 arc second ASTER GDEM version 1 and version 2 by METI-NASA in comparison with ground control points from 1:50000 digital line graphs for the coastal zone of Shandong Province, Easter China. The vertical accuracy of SRTM $D E M$ is $13.74 \mathrm{~m}$ root mean square error (RMSE), and GDEM version 1 reaches $24.11 \mathrm{~m}$ RMSE. Version 2 of ASTER GDEM shows better performance than version 1 and SRTM DEM with a RMSE of $12.12 \mathrm{~m}$. A strong correlation of the magnitude of elevation error with slope and elevation is identified, with lager error magnitudes in the steeper slopes and higher elevations. Taking into account slope and elevation has the potential to considerably improve the accuracy of the SRTM DEM and GDEM version 1 products. However, this improvement for GDEM version 2 can be negligible due to their limited explanatory power for the DEM elevation errors.
\end{abstract}

Keywords: Elevation errors, SRTM DEM, ASTER DEM

\section{INTRODUCTION}

Chinese coastal zones are vulnerable to coastal flooding resulting from future sea-level rise due to the rapid developments of densely populated deltas and large growing cities [13]. The threats are becoming potentially strong because of the predicted sea level rise of over $1 \mathrm{~m}$ in this century [16]. A high resolution DEM can three-dimensionally represent beach erosion, flooding, and natural and man-made features on the coastal zones. This will enable us to better understand the associated vulnerability and risks and determine our responses to the risks. A high precise DEM is also required for hydrological studies $[1,11,28]$, glacial mass loss assessment [14], orthorectification of satellite images [27], vegetation cover studies [18], and spatial dataset construction (e.g., gridded surface temperature and stable isotopic composition over Antarctica) [25, 26]. In general, DEM data sets can be created by means of ground survey, photogrammetric techniques, radar altimetry, radar interferometry, and stereoscopic pairs. Among them, Spaceborne Interferometric SAR (InSAR) and stereoscopic pair from Earth Observation Satellites are two promising technologies for obtaining elevation information at a global or regional scale.

In February 2000, the Shuttle Radar Topography Mission (SRTM) spearheaded by the National Geospatial-Intelligence Agency (NGA), NASA, the Italian Space Agency (ASI) and the German Aerospace Center (DLR) provides the first spatially continuous elevation information covering more than $80 \%$ of the Earth's land [15].The SRTM data has a spatial resolution of 3 arc second (approximately $90 \mathrm{~m}$ ) which is available for the Earth land between latitudes $57 \mathrm{oS}$ and $60 \mathrm{oN}$, and 1 arc second (approximately $30 \mathrm{~m}$ ) only for the United States. Despite global coverage of SRTM data, considerable voids occur in water-body and some steep mountainous regions due to the incorrect radar reflection, and excessive atmospheric interference coherence [10]. The voids impede the utilization of the SRTM data for certain applications, for instance, for hydrological modeling. Many attempts have been made to fill the data gaps by spatial 
filters, iterative hole filling, and interpolation techniques developed by the Consortium for Spatial Information of the Consultative Group for International Agricultural Research (CSI-CGIAR) [9], since the first release of SRTM data set in 2004. The latest refined SRTM DEM (version 4.1) by CSICGIAR is available at no charge for any users at: http://srtm. csi.cgiar.org/. While many validations of this product have been performed at global and regional scales due to its great potential use $[5,7,19]$, more regional evaluations would give more benefits to global users due to the various SRTM elevation biases from one region to another.

Recently, much attention has been paid to the release in July 2009 and October 2011 of the Global Digital Elevation Models (GDEM) generated from Advanced Spaceborne Thermal Emission and Reflection Radiometer (ASTER) stereo images by the Ministry of Economy, Trade, and Industry (METI) of Japan and the United States National Aeronautics and Space Administration (NASA) due to their free and widespread accessibility. Compared to the SRTM DEM, ASTER GDEM has a higher spatial resolution (about $30 \mathrm{~m}$ ), and a wider land surface coverage $\left(83^{\circ} \mathrm{N}-83^{\circ} \mathrm{S}\right)$, especially covering some high latitude and steep mountainous regions beyond the coverage of SRTM. ASTER GDEM is therefore expected to be one of the best sources of global topographic data for various scientific applications. At a global scale, the elevation accuracy of version 1 of ASTER GDEM is estimated at 95\% confidence as 20 meters by a comparison of ASTER GDEM with other reliable datasets [2]. Moreover, the version 2 greatly improved its accuracy upon version 1 . Despite of much improvement of ASTER DEM, at local scale, it is still important to perform a case-by-case verification of the precision of GDEM data for understanding the potential and limitations in its application in a specific region.

Our main objective is to evaluate the quality of SRTM DEM (version 4.1) and ASTER GDEM version 1 and version 2 in terms of vertical accuracy in the coastal zone of Shandong Province, China using ground control points from 1:50000 topographic maps.

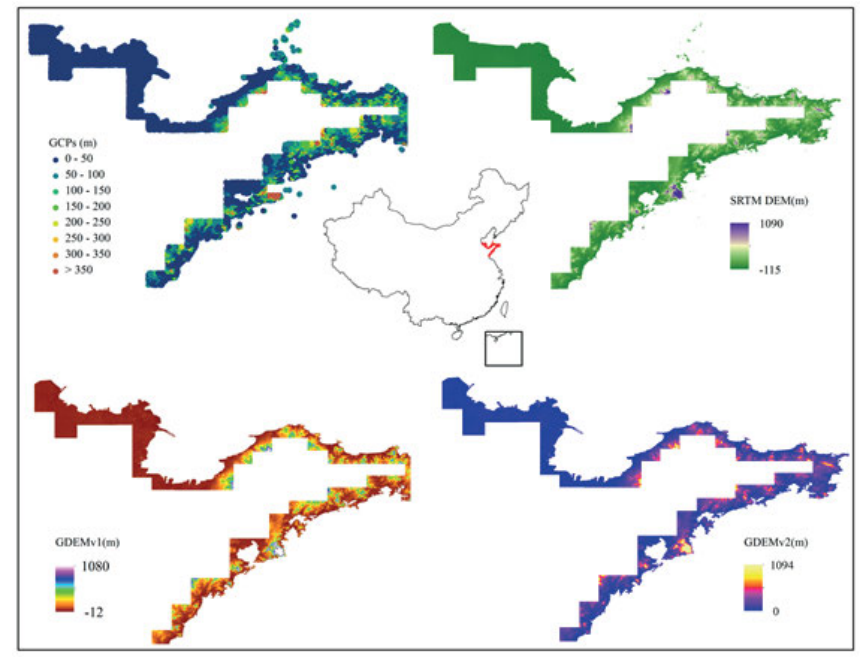

Fig. 1. Location of study area, ground control points (GCPs) from 1:50000 digital line graphs, SRTM DEM, ASTER GDEM version 1 and ASTER DEM version 2

\section{STUDY AREA}

Our study focuses in the coastal zone of Shandong Province, located at the East China seaboard and lower reach of the Yellow River (Fig. 1). It faces the Bohai Sea in the north, and the Yellow Sea in the east. With a total length of $3024 \mathrm{~km}$, coastline of Shandong Province accounts for one sixth of total length in China. The relief varies from the Yellow River delta plain in the northwest, and coastal plain in the southeast, to hilly regions along the eastern peninsula. The elevations range from 0 (in some areas a few metres below mean sea level) to more than $800 \mathrm{~m}$ above sea level.

\section{DATA AND METHODS}

The version 4.1 SRTM DEM is the latest version postprocessed by CSI-CGIAR. The data set improves significantly on the original versions by filling voids based on the new interpolation algorithms and better additional DEMs $[8,9]$. In addition, in this data set, the high resolution shoreline information generated by the US Geological Survey [23] was used to distinguish land and ocean regions. The SRTM DEMs are provided in $5^{\circ} \times 5^{\circ}$ tiles with both Arc-Info ASCII format and GeoTiff.

ASTER GDEM version 1 (GDEMv1) was generated from VNIR Band 3N of all the existing ASTER images during 19992008. The data are available for easy download as $1^{\circ} \times 1^{\circ}$ tiles at 1 arc-second $(30 \mathrm{~m})$ resolution with geographic lat/long coordinates. A quality assessment file is included in each $1^{\circ} \times 1^{\circ}$ tile to demonstrate the number of images used for the elevation generation at each pixel and the location if elevation anomalies have been corrected. Preliminary validation of GDEMv1 showed the vertical accuracy with a root mean square error (RMSE) of 10-25 m [2]. However, GDEMv1 contains some significant anomalies resulting from cloud, artifacts associated with irregular stack boundaries such as pits, bumps and mole runs, and water masking issues [2]. A new version of the ASTER GDEM (GDEMv2) with the same grid and tile structure as GDEMv1 was released in mid-October, 2011 by the joint of NASA and METI. The voids and artifacts in GDEMv2 greatly declined, even eliminated in some regions by the improvement in spatial coverage using 260000 additional scenes, spatial resolution based on a smaller correlation kernel, and water masking [3].

To explore the difference in SRTM DEM and GDEM, 13244 ground control points (GCPs) were collected from elevation point layer of 1:50000 digital line graphs (DLGs) derived from vertical aerial photographs. The horizontal accuracy of GCP was estimated to be less than $25 \mathrm{~m}$ and vertical accuracy less than $2.5 \mathrm{~m}$ [20].The GCP elevation data were initially referenced to the 1985 Yellow Sea Datum, and horizontally georeferenced to the Xi'an 1980 reference system, while the datum of SRTM DEM and GDEM is WGS 1984 with EGM96. The GCP locations were converted to WGS 1984 reference system using a seven seven-parameter spatial transform model. The error of coordinate conversion was less than $0.02 \mathrm{~m} \mathrm{[24].}$ A vertical transformation between 1985 Yellow Sea Datum and EGM96 are not required due to their negligible difference 
(a few centimeters in East China, [29, 30]) for SRTM and GDEM accuracy assessment.

Vertical accuracies of SRTM DEM and GDEM were assessed by comparing the difference between the GCP elevation and the corresponding DEM value. Since the GCPs are not directly in accord with a DEM point location, for every control point location, the corresponding DEM elevation was extracted through the bilinear interpolation. Positive differences mean the interpolated DEM elevation was below the GCP elevation. Negative errors represent the locations where the DEM elevation was above GCP elevation. Three dimension spatial analysis tools available at the commercial software ArcGIS version 9.3 were applied to calculate the slope and slope aspect of SRTM DEM and GDEM at the location of each GCP. The extracted slope aspect were classified to one category with a value of -1 for flat terra and 8 categories with a width of $45^{\circ}$ (i.e., North, Northeast, East, Southeast, South, Southwest, West and Northwest). Summary statistics of SRTM DEM and GDEM errors are expressed by the standard deviation, mean absolute error and root mean square error. We also quantified the relationship between the errors and topographic variables such as altitude, slope, and aspect using the software SPSS 13.

\section{RESULTS}

\section{ACCURACY OF SRTM DEM, GDEMV1, AND GDEMV2}

Fig. 2 shows frequency distribution of SRTM DEM, GDEMv1, and GDEMv2 errors determined from a comparison to GCP elevations from 1:50000 scale topographic maps. Table 1 quantifies the accuracy of the SRTM DEM, GDEMvl and GDEMv2 for the coast zones of Shandong Province. The errors of SRTM DEM, GDEMv1 and GDEMv2 ASTER exhibit similar frequency distribution patterns with the more number of positive errors than the negative (Fig. 2). However, the errors of SRTM DEM and GDEMv2 are more concentrated at near medium values than those of GDEMvl. Furthermore, the range of GDEMvl error with a maximum of $169 \mathrm{~m}$, and a minimum of $-49 \mathrm{~m}$ is broader than other two DEMs. The basic statistics for these difference shows that the mean SRTM DEM elevations are about $7.1 \mathrm{~m}$ lower than GCP elevations, ASTER GDEMv1 are about $12.3 \mathrm{~m}$ lower, and GDEMv2 are around $3.8 \mathrm{~m}$ lower, implying a general underestimation of topographic elevation by the SRTM DEM, GDEMv1 and GDEMv2 (Fig. 2 and Table 1).
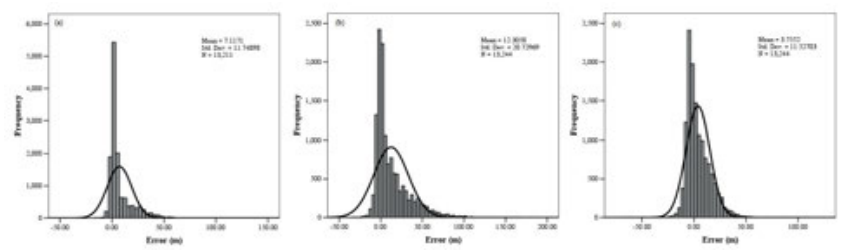

Fig. 2. Error distribution histogram of (a) SRTM DEM; (b) GDEMv1; (c) GDEMv2

The accuracy of SRTM DEM as determined using our benchmarks is $11.75 \mathrm{~m}$ standard deviation, and $13.74 \mathrm{~m}$ RMSE. GDEMv1 presents relative large residual errors with a standard deviation of $20.72 \mathrm{~m}$ and an RMSE of $24.11 \mathrm{~m}$. Compared to the GDEM version 1, the accuracy of version 2 (GDEMv2) greatly improved with $11.52 \mathrm{~m}$ standard deviation and $12.12 \mathrm{~m}$ RMSE. Linear regression of the relationships between GCP elevations and SRTM DEM, GDEMv1 and GDEMv2 yields very high determination coefficients of $0.991,0.966$ and 0.988 , respectively (not shown), and thus there are significant correlations between GCP elevations and the three DEMs. All the slopes of the regression lines slightly below 1 probably show that the three DEMs tend to increasingly underestimate GCP elevation with increasing elevation.

Tab. 1. Statistical analysis of the deviation of SRTM DEM, ASTER GDEM version 1 and version 2 from GCP data

\begin{tabular}{lccccc}
\hline \multicolumn{1}{c}{ Comparison } & Mean & Standard deviation & RMSE & Minimum & Maximum \\
\hline GCPs-SRTM & 7.11 & 11.75 & 13.74 & -30 & 150 \\
GCPs-GDEMv1 & 12.31 & 20.72 & 24.11 & -49 & 166 \\
GCPs-GDEMv2 & 3.76 & 11.53 & 12.12 & -69 & 109 \\
\hline
\end{tabular}

\section{RELATIONSHIP OF ELEVATION ERROR WITH ELEVATION IN DEMS, SLOPE AND ASPECT}

Plots of the elevation errors vs. elevations in the three DEMs and slope angle indicate strong positive correlations between the magnitudes of elevation error and both elevation and slope angle (Fig. 3). To estimate the strength of the relationships, we calculated the goodness of linear fit (R2, the coefficient of determination), which gives the amount of the variation in one variable that can be accounted for by another variable. The slope angle explained $70.2 \%$ of the SRTM DEM elevation error variance. $59.2 \%$ of the variation of elevation error magnitudes can be accounted for by elevation in SRTM DEM. For GDEMv1, the slope angle and elevation account for $64.8 \%$ and $44.6 \%$ of the variation in elevation error magnitudes, respectively. However, the slope angle and elevation has little explanatory power for the GDEMv2 elevation errors. A multiple regression model based on the variables used to predict the elevation errors in the three DEMs are expressed as follows:

$$
\text { elevation error }=\text { aslope }+\beta \text { elevation }+\varepsilon \text {. }
$$

Where $\alpha$ and $\beta$ are model coefficients, and $\varepsilon$ is residual. The overall adjusted R-squared is 0.723 for SRTM DEM elevation error model, 0.673 for GDEMv1 error model, only 0.348 for GDEMv2 elevation error model.

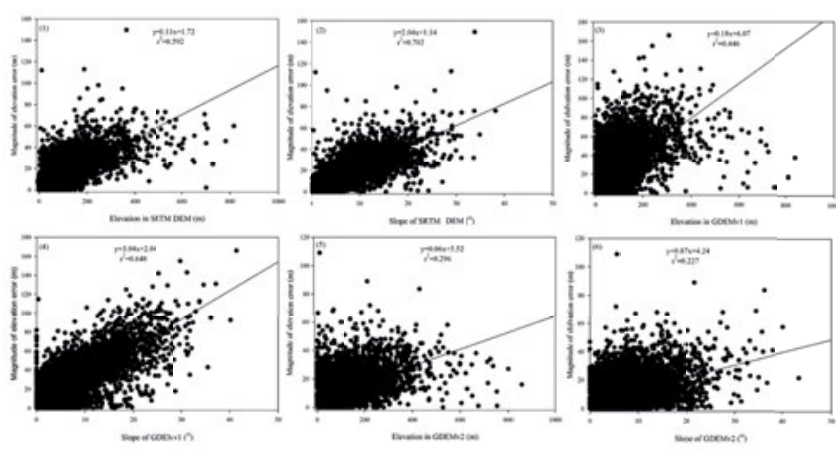

Fig.3. Plots showing relationship between the elevation error magnitudes of SRTM DEM, GDEMv1 and GDEMv2 and slope angle and elevation 
Although there is no significant correlation between elevation error and slope aspect, elevation accuracy of SRTM and GDEMv1 varies greatly at different direction classes (Fig. 4). SRTM DEM has the best elevation accuracy in the East with a RMSE of about $6.5 \mathrm{~m}$, standard deviation of $6 \mathrm{~m}$ and mean absolute error (MAE) of about $3.5 \mathrm{~m}$, and worst accuracy in the West with about $18 \mathrm{~m}$ RMSE, $14 \mathrm{~m}$ standard deviation and 12 m MAE. For GDEMvl, the values of RMSE are approximately $14 \mathrm{~m}$ in the South and Southeast, increases for West and East, and reaches the maximum of approximately $40 \mathrm{~m}$ for the North. The mean absolute error and standard deviation exhibit a similar pattern. Similar elevation error in each direction for GDEMv2 shows the aspects do not significantly affect the elevation accuracy of GDEMv2 (Fig.4).

Variance in elevation error explained by slope is strongly linked with magnitude of elevation errors in aspect category: the larger the error in the class aspect is, the more variance in elevation error accounted for by slope is (Fig.4). For instance, the variance of SRTM elevation error explained by slope angle reaches $76.4 \%$ in the Northwest, corresponding to the maximum error in the aspect.

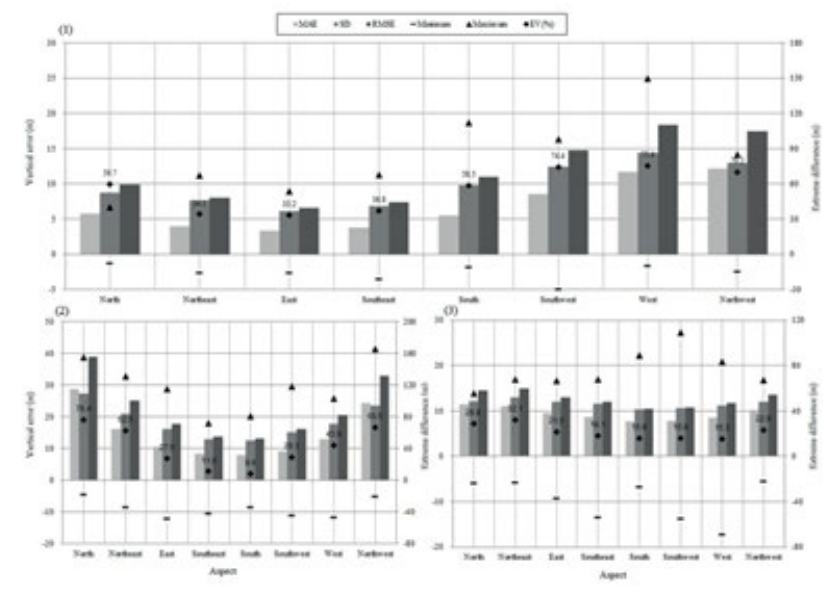

Fig. 4. Basic statistics of the vertical accuracy of the SRTMDEM version 4.1, ASTER GDEM version 1 and ASTER GDEM version 2 across all aspects (MAE: mean absolute error; SD: standard deviation, RMSE: and EV: explained variance by slope)

\section{DISCUSSION}

SRTM DEM and ASTER GDEMv1 and GDEMv2 closely correspond to GCP elevation from 1:50000 scale topographic maps. However, there is still a negative bias in the SRTM DEM and ASTER GDEM elevations with respect to the GCPs. The difference between the Yellow Sea Datum and WGS84-EGM96 heights may at least partly contribute to the phenomenon.

While officially stated vertical accuracy of SRTM DEM is $\pm 16 \mathrm{~m}$ at $90 \%$ confidence, global accuracy varies over different regions $[17,21]$. The accuracy of SRTM DEM in Eurasia is $16.09 \mathrm{~m}$ standard deviation in comparison with satellite radar altimetry [4]. Based on GCPs, vertical errors are estimated to be about $6 \mathrm{~m}$ in the Western Australia [7], $8.5 \mathrm{~m}$ (at 90\% confidence) for North America [8, 23]. Centimeter-accurate real-time kinematic GPS (RTK-GPS) surveying indicated SRTM DEM elevation error in North Greek is $6.4 \mathrm{~m}$ [9], 7.58 $\mathrm{m}$ in Phuket (USA) [5], and 4.07m in Catskillsa (Thailand) [5]. This study yields elevation errors in SRTM DEM for coastal zones of Shandong Province with a standard deviation of $11.75 \mathrm{~m}$ by the comparison of GCP elevation and bilinear interpolation of DEM.

There are artifacts and residual anomalies in the ASTER GDEMv1, and thus it is regarded as "experimental" or "research grade." In the GCP comparisons, GDEMv1 showed the lowest accuracy with RMSE values of about $24 \mathrm{~m}$. However, this still agrees with the above mentioned accuracy range of GDEMv1 elevations (10-25 m RMSE, ASTER Validation Team, 2009). GDEMv2 greatly improved its accuracy with a RMSE of 12.12 $m$ on the version 1 , in accord with the validation by the joint effort between Japan and the United States [3].

The accuracy of the three DEMs decreased as surface slope became steeper, and the elevation became higher, agreeing with the previous studies that surface relief play an important role in the DEM accuracy $[5,19,22,30]$. The impact of surface slope appears to be much more profound than the contribution of elevation for the accuracy of SRTM DEM and GDEMvl because of large errors occurring at low elevations with considerable slopes. However, elevation explains more variance of GDEMv2 error than slope despite of their limited explanatory power (Fig. 3). Slope and elevation data derived from the SRTM DEM and GDEMvl can better predict the elevation errors in the two DEMs. A multiple regression model based on the variables explained $72.3 \%$ and $67.3 \%$ of the total variation in SRTM error and GDEMv1 error, respectively.

\section{CONCLUSION}

This study evaluated the quality of SRTM DEM, ASTER GDEMv1 and GDEMv2 and their accuracy as a function of slope and elevation. GDEMv2 generally proved to be more accurate than SRTM DEM and GDEM. Incorporating slope and elevation into a multiple regression model will substantially improve the accuracy of SRTM DEM and GDEM. Due to the higher resolution, fewer voids and higher accuracy than SRTM DEM, GDEM version 2 would be widely used in coastal environment studies.

\section{ACKNOWLEDGMENTS}

Funding this study was from CAS "Strategic Priority Research Program-Climate Change: Carbon Budget and Relevant Issues" (XDA05130703), China Academy of Sciences Key deployment project (KZZD-EW-14), and Shandong province High School Science \& Technology Project (J11LE12).

\section{REFERENCES}

1. Andersson, J.O. Nyberg, L., Using official map data on topography, wetlands and vegetation cover for prediction of stream water chemistry in boreal headwater catchments, Hydrology and Earth System Science, Vol.13, pp. 537-549, 2009. 
2. ASTER GDEM Validation Team, ASTER global DEM validation summary report. METI \& NASA, 28pp, 2009.

3. ASTER GDEM Validation Team, ASTER global DEM validation summary report. METI \& NASA, 25pp, 2011

4. Berry, P. A. M., Garlick, J. D., Smith, R. G., Near-global validation of the SRTM DEM using satellite radar altimetry, Remote Sensing of Environment, Vol. 106, pp. 17-27, 2007.

5. Gorokhovich, Y., Voustianiouk, A., Accuracy assessment of the processed SRTM-based elevation data by CGIAR using field data from USA and Thailand and its relation to the terrain characteristics, Remote Sensing of Environment, Vol. 104, pp. 409-415, 2006.

6. Guo, H., Jiao, W., Yang, Y., Liu, G., Systematic error of the 1985 National Height Datum, Geomatics and Information Science of Wuhan University, Vol. 29, pp.715-719, 2004.

7. Hirt, C., Filmer, M. S., Featherstone, W. E., Comparison and validation of the recent freely available ASTERGDEM ver1, SRTM ver4.1 and GEODATA DEM-9S ver3 digital elevation models over Australia, Australia Journal of Earth Sciences, Vol. 57, pp. 337-347, 2010.

8. Jarvis, A., Reuter, H. I., Neson, A., Guevara, E., Hole-filled SRTM for the globe Version 4, Available from the CGIARSXI SRTM 90m database: http://srtm.csi.cgiar.org, 2008.

9. Jarvis, A., Rubiano, J., Nelson, A., Farrow, A., Mulligan, M., Practical use of SRTM data in the tropics - Comparisons with digital elevation models generated from cartographic data, Working Document No. 198. Cali, International Centre for Tropical Agriculture (CIAT): 32 pp, 2004.

10. Kääb, A., Combination of SRTM3 and repeat ASTER data for deriving alpine glacier flow velocities in the Bhutan Himalaya, Remote Sensing of Environment, Vol. 94, pp. 463-474, 2005.

11. Lin, S., Jing, C., Chaplot, V., Yu, X., Zhang, Z., Moore, N., Wu, J., Effect of DEM resolution on SWAT outputs of runoff, sediment and nutrients, Hydrology and Earth System Science Discussion, Vol. 7, pp. 4411-4435, 2010.

12. Mouratidis, A., Briole, P., Katsambalos, K., SRTM 3" DEM (versions 1, 2, 3, 4) validation by means of extensive kinematic GPS measurements: a case study from North Greece, International Journal of Remote Sensing, Vol. 31, pp. 6205-6222, 2010.

13. Nicholls, R. J., Cazenave, A., Sea-level rise and its impact on coastal zones, Science, Vol. 328, pp.1517-1519, 2010.
14. Peduzzi1, P., Herold, C., Silverio, W., Assessing high altitude glacier thickness, volume and area changes using field, GIS and remote sensing techniques: the case of Nevado Coropuna (Peru), The Cryosphere, Vol. 4, pp. 313-323, 2010.

15. Rabus, B., Eineder, M., Roth, A., Bamler, R., The shuttle radar topography mission-a new class of digital elevation models acquired by spaceborne radar, ISPRS Journal of Photogrammetry and Remote Sensing, Vol. 57, pp. 241-262, 2003.

16. Rahmstorf S., A new view on sea level rise, Nature Reports: Climate Change, Vol. 4, pp. 44-45, 2010.

17. Rodriguez, E., Morris, C. S., Belz, J. E., Chapin, E. C., Martin, J. M., Daffer,W., Hensley S., An assessment of the SRTM topographic products, Technical Report JPL D-31639. Pasadena, California: Jet Propulsion Laboratory 143 pp, 2005.

18. Sharma, B. D., Clevers, J., De Graaf, R., Chapagain, N. R., Assessing the land cover situation in Surkhang, Upper Mustang, Nepal, using an ASTER image, Him. J. Sci., Vol. 1, pp. 93-98, 2003.

19. Shortridge, A., Messina, J., Spatial structure and landscape associations of SRTM error, Remote Sensing Environment, Vol. 115, pp.1576-1587, 2011.

20. State Bureau of Technical Supervision: Specifications for aerophotogrammetric office operation of 1:25000, 1:50000, 1:100000 topographic maps, Beijing: Standards Press of China, 2008.

21. Suna, G., Ransonb, K. J., Kharukc, V. I., Kovacsd, K., Validation of surface height from shuttle radar topography mission using shuttle laser altimeter, Remote Sensing Environment, Vol. 88, pp. 401-411, 2003.

22. Toutin T., Impact of terrain slope and aspect on radargrammetric DEM accuracy, ISPRS Journal of Photogrammetry and Remote Sensing, Vol. 57, pp. 228$240,2002$.

23. US Geological Survey, SRTM Water Body Data Set, Web document. http://edc.usgs.gov/products/elevation/swbd. html (accessed 28.July 2009), 2003.

24. [24] Wang, J. X., Wang, J., Lu, C. P., Problem of coordinate transformation between WGS-84 and BEIJING 54, Journal of Geodesy and Geodynamics, Vol. 23, pp. 70-73, 2003. (In Chinese)

25. Wang, Y., Hou, S., Masson-Delmotte, V., Jouzel, J., A generate additive model for the spatial distribution of stable isotopic composition in Antarctic surface snow, Chemical Geology, Vol. 271, pp.133-141, 2010. 
26. Wang, Y., Hou, S., Spatial distribution of $10 \mathrm{~m}$ firn temperature in the Antarctic Ice Sheet, Science in China: Earth Science, Vol. 54, pp. 655-666, 2011.

27. Wang, Y, Hou, S., Liu, Y., Glacier change in the Karlik Mountain, Eastern Tien Shan during 1971/72-2001/02 using remote sensing data and GIS technology, Annals of Glaciology, Vol. 50, pp.39-45, 2009.

28. Wechsler, S. P., Uncertainties associated with digital elevation models for hydrologic applications: a review, Hydrology and Earth System Science, Vol. 11, pp.14811500, 2007.

29. Zhai, Z., Wei, Z., Wu, F., Ren, H., Computation of vertical deviation of Chinese height datum from geoid by using EGM 2008 model, Journal of Geodesy and Geodynamics, Vol. 31, pp.116-118, 2011. (In Chinese)

30. Zhao, S., Cheng, W., Zhou, C., Chen, X., Zhang, S., Zhou, Z., Liu, H., and Chai, H., Accuracy assessment of the ASTER GDEM and SRTM3 DEM: an example in the Loess Plateau and North China Plain of China, International Journal of Remote Sensing, Vol. 32, pp. 8081-8093, 2011.

\section{CONTACT WITH AUTHOR}

\author{
Shaopeng Luan \\ Xiyong Hou \\ Yantai Institute of Coastal Zone Research \\ Chinese Academy of Sciences \\ Yantai \\ 264003 China \\ Yetang Wang \\ College of Population, \\ Resources and Environment, \\ Shandong Normal University, \\ Jinan, \\ 250014, China \\ tel.: +8653186180646 \\ fax.: +8653186180646 \\ e-mail: wangyetang@163.com \\ Shaopeng Luan \\ University of Chinese Academy of Sciences, \\ Beijing \\ 100049 China \\ Shaopeng Luan \\ Geomatics Center of Yantai City
}

